\title{
Characteristics and relationship dynamics of male partners of adolescent girls and young women in Malawi
}

Project SOAR

Follow this and additional works at: https://knowledgecommons.popcouncil.org/departments_sbsr-hiv

Part of the Public Health Commons

How does access to this work benefit you? Let us know!

\section{Recommended Citation}

Project SOAR. 2021. "Characteristics and relationship dynamics of male partners of adolescent girls and young women in Malawi," Project SOAR Results Brief. Washington, DC: Population Council. 


\section{Characteristics and Relationship Dynamics of Male Partners of Adolescent Girls and Young Women in Malawi}

In Malawi, HIV prevalence among adolescent girls and young women (AGYW), aged 15-24, is 2.3 times higher than among young men of the same age (3.4 percent vs. 1.5 percent). ${ }^{1}$ As in many countries, AGYW in Malawi are particularly vulnerable to HIV for a variety of reasons, including economic disadvantage and unequal power dynamics in sexual relationships with their male partners-many of whom are older and engage in high-risk behaviors. ${ }^{2}$ Additionally compared to women, men are less likely to know their HIV status, initiate HIV treatment, and are more likely to die of AIDS ${ }^{2,3}$-harming both themselves and their partners.

Project SOAR conducted research in 2019 among men in Malawi to learn more about their relationships with AGYW and how HIV services can better engage them.

Researchers surveyed 612 men ages 18 or older recruited at community hotspot venues and HIV service sites. Key inclusion criteria were being in an intimate or sexual relationship with an AGYW and residing in Zomba or Machinga districts.

This brief summarizes findings on men's characteristics, the types and dynamics of their sexual relationships, and their vulnerabilities and environmental stressors. A companion brief highlights data on men's knowledge of HIV and condoms, use of HIV-related services, stigma, and exposure to PEPFAR's DREAMS (Determined Resilient Empowered AIDS-free Mentored and Safe) program which took a multi-sectoral approach to reduce HIV risk among AGYW and their male partners. ${ }^{4}$

\section{WHO WERE THE RESPONDENTS?}

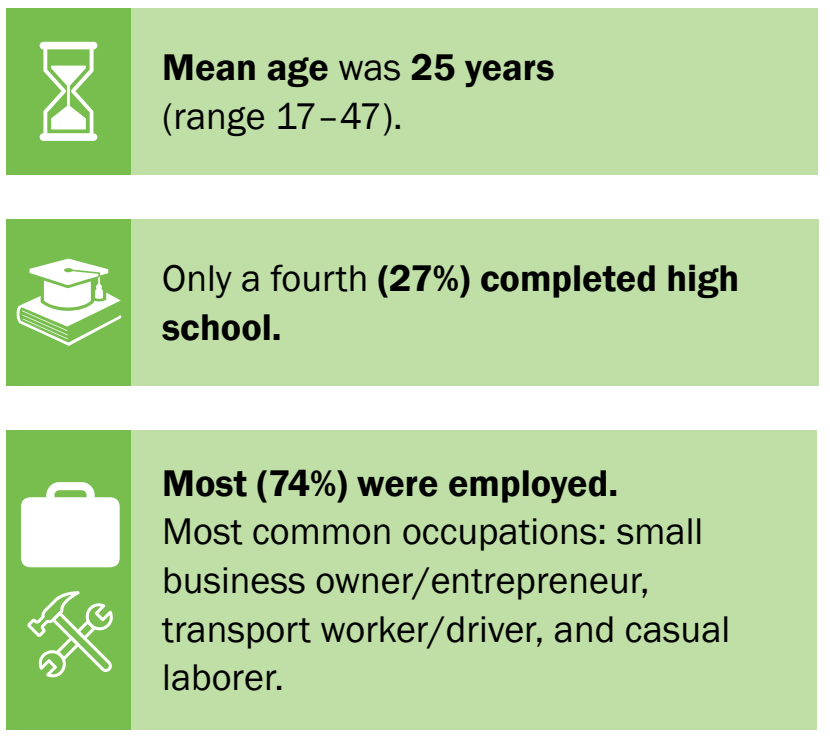

Interested in learning more about the male partners of AGYW? See the companion brief:

HIV knowledge, service utilization, and exposure to DREAMS among male partners of adolescent girls and young women in Malawi

Available at projsoar.org/our-activities/malawidreams/ 


\section{RESULTS}

\section{Multiple partnerships are very common, but condom use is not.}

About half of men (46 percent) were married and another 40 percent were dating someone but not living together. More than half of all men (59 percent) had two or more female partners in the last year. The number of partners ranged from 1 to 23. About a fourth ( 23 percent) had three or more AGYW partners in the last year. Almost a fifth (17 percent) had both AGYW partners and partners age 25 or older. Only 44 percent reported using a condom at last sex with their current or most recent partner.

\section{Male partners of AGYW are not just "sugar daddies."}

The mean age difference between AGYW and their partners was 4.4 years. Very few men (4 percent) reported that the age difference was 10 or more years for each of their last three partners.

\section{Many men engage in transactional relationships.}

Almost a half (43 percent) said they gave money, goods, or services to start or stay in a sexual relationship with their most recent partner. Among these men, about a fourth (24 percent) said the transactions were critical for maintaining these relationships. When asked about their three most recent partners, nearly two-thirds (65 percent) reported transactional sex with any of these partners.

\section{Anger, conflict, and violence often characterize men's sexual relationships.}

Figure 1 highlights the role anger and conflict play in men's communication with their partners. Some are also perpetrators of physical violence (17 percent reported ever being physically violent toward their current or most recent partner) and sexual violence (19 percent said they had forced this partner to have sex).

\section{Figure 1 Relationship communication and conflict}

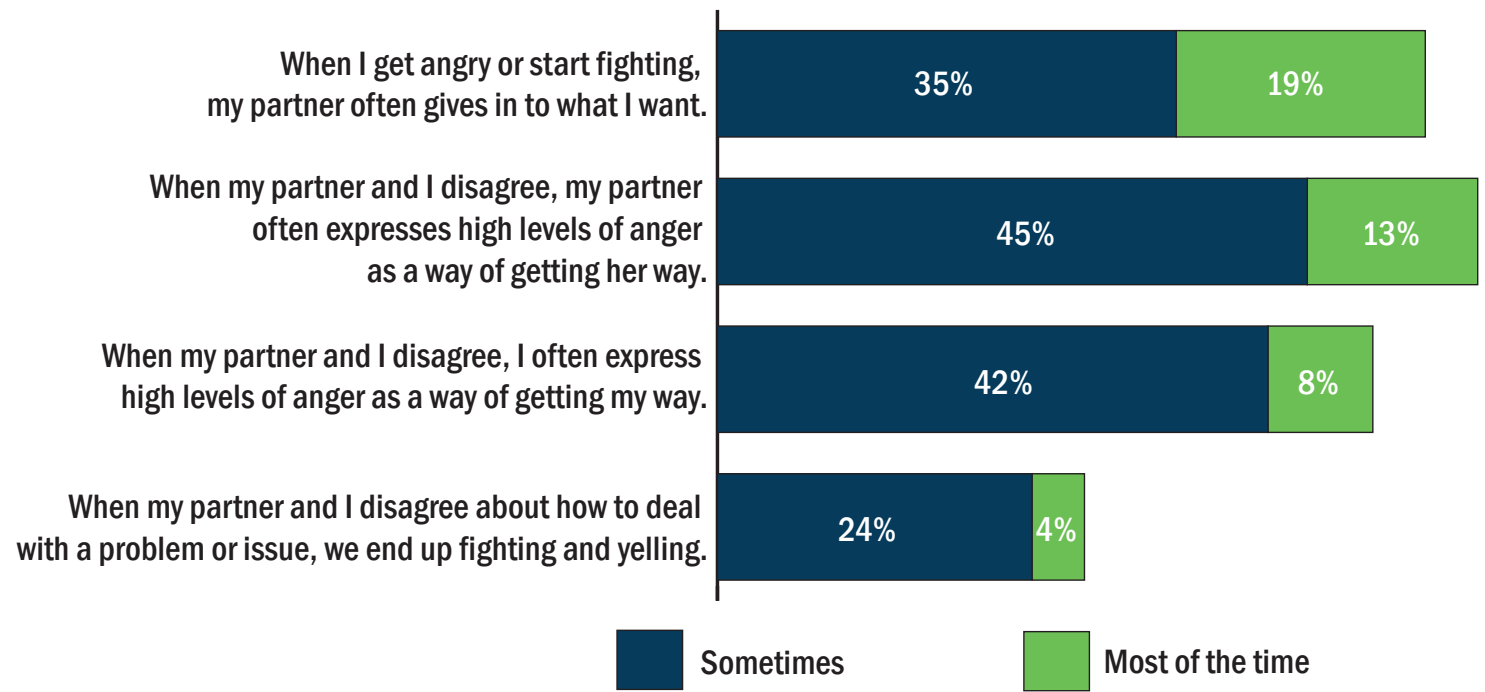




\section{Men express limited support for gender equity.}

For three out of the four items shown in Figure 2, the majority of men agree or partially agree with gender inequitable statements about women's roles and responsibilities.

\section{Figure 2 Attitudes toward women's roles and responsibilities}

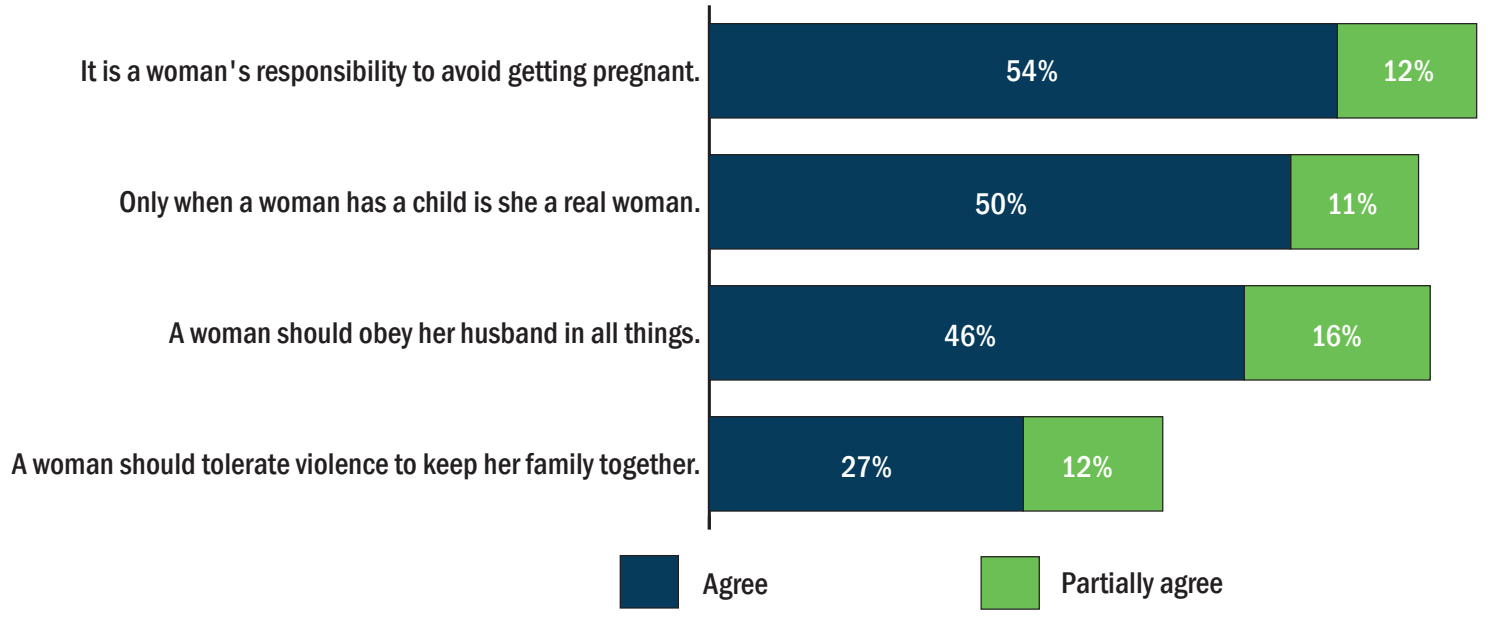

\section{Men experience depression and alcohol abuse.}

As shown in Figure 3, 35 percent of men had moderate or severe depression. Nearly half (45 percent) of men in the sample indicated they drank alcohol. Among these men, 23 percent said they would drink six or more drinks on one occasion at least weekly and another 20 percent monthly.

\section{Figure 3 Depression}

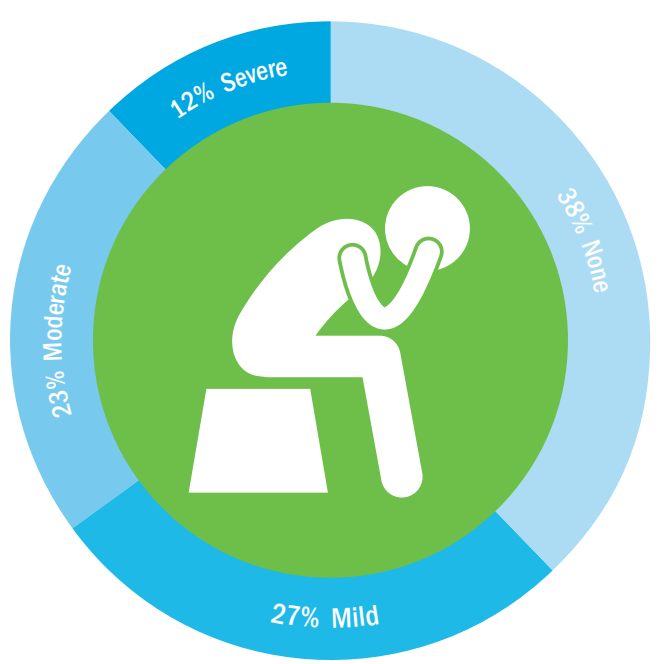




\section{REFERENCES}

1. Ministry of Health Malawi. 2018. "Malawi Population-based HIV Impact Assessment (MPHIA) 2015-2016: final report." Lilongwe: Ministry of Health.

2. UNAIDS. 2016. Prevention GAP report. Geneva: UNAIDS.

3. UNAIDS 2017. "Blind spot-Reaching out to men and boys." Geneva: UNAIDS. https://www. unaids.org/sites/default/files/media_asset/ blind_spot_en.pdf

4. Saul, J et al. 2018. “The DREAMS core package of interventions: A comprehensive approach to preventing HIV among adolescent girls and young women," PLOS ONE 13(12): e0208167. doi: 10.1371/journal.pone.0208167

5. Kurt Kroenke, Robert L. Spitzer, Janet B.W. Williams, Bernd Löwe. 2009. “An ultra-brief screening scale for anxiety and depression: the PHQ-4," Psychosomatics 50(6): 613-621. doi: 10.1016/S0033-3182(09)70864-3.

Suggested citation: Project SOAR. 2021. "Characteristics and relationship dynamics of male partners of adolescent girls and young women in Malawi," Project SOAR Results Brief. Washigton, DC: Population Council.

Project SOAR is a six-year+ (September 2014-January 2021) cooperative agreement funded by the United States President's Emergency Plan for AIDS Relief and the U. S. Agency for International Development (Agreement No. AID-OAA-A-14-00060). The contents of this brief are the sole responsibility of Project SOAR and Population Council and do not necessarily reflect the views of PEPFAR, USAID, or the United States Government.

Population Council leads the Project SOAR consortium in collaboration with Avenir Health, Elizabeth Glaser Pediatric AIDS Foundation, the Johns Hopkins University, Palladium, and The University of North Carolina at Chapel Hill.
Project SOAR/Population Council 4301 Connecticut Avenue, NW, Suite 280 Washington, DC 20008

Tel: +1202 2379400

e-mail: ProjectSOAR@popcouncil.org projsoar.org

(c) Population Council, January 2021 